\title{
Natureza incomum: histórias do antropo-cego
}

[ Uncommoning nature: stories from the Anthropo-not-seen

\section{Marisol de la Cadena ${ }^{\mathrm{I}}$}

Sou grata pelos comentários que recebi de Judy Farquhar, Cristiana Giordano, Stefanie Graeter, John Law, Casper Bruun Jensen e Brit Winthereik. Tradução de Jamille Pinheiro Dias.

\begin{abstract}
RESUMO $\cdot O$ aumento do consumo de minerais e energia levou a uma destruição sem precedentes do que conhecemos como natureza e dos recursos a ela associados, geralmente localizados em territórios habitados por grupos indígenas que reagem politicamente a essa destruição, somando forças com movimentos que protestam contra a devastação do meio ambiente. Conceituando uma política radicalmente diferente como "natureza incomum", a autora apresenta o que chama de "antropo-cego": um processo de criação de mundo por meio do qual mundos heterogêneos que não se fazem com uma divisão entre humanos e não humanos são obrigados a operar com essa distinção, ao mesmo tempo que a excedem. PALAVRAS-CHAVE . Antropoceno; antropo-cego; comum; humanos;
\end{abstract}

não humanos. · ABSTRACT · Increasing consumption of minerals and energy has led to an unprecedented destruction of what we know as nature and natural resources, usually located in territories inhabited by indigenous groups who respond politically to this destruction, joining movements that protest the destruction of the environment. Conceptualizing a radically different politics as "uncommoning nature", the author presents what she calls the "anthropo-notseen": a worldmaking process through which heterogeneous worlds that do not make themselves through the division between humans and nonhumans are both obliged into that distinction and exceed it. - KEYWORDS . Anthropocene; Anthropo-not-seen; common; humans; nonhumans.

Recebido em I7 de novembro de 2017

Aprovado em II de março de 2018

DE LA CADENA, Marisol. Natureza incomum: histórias do antropo-cego. Revista do Instituto de Estudos Brasileiros, Brasil, n. 69, p. 95-II7, abr. 2018.

DOI: http://dx.doi.org/Io.II6o6/issn.23I6-90IX.voi69p95-II7

I Universidade da Califórnia - Davis (UC Davis, Califórnia, EUA). 


\section{UM PREÂMBULO}

No dia 5 de junho de 2009, ao amanhecer, perto da cidade de Bagua, no norte amazônico, forças policiais e um grande grupo de cidadãos peruanos autoidentificados como pertencentes ao grupo indígena AwajunWampi entraram em confronto. Esse acontecimento, que resultou em mais de 30 mortes, marcou o imaginário político com diferentes sentidos, dependendo de a posição ser de esquerda ou direita no espectro político nacional. No geral, a narrativa que circula na mídia é a seguinte: como parte de uma greve geral, que começou em 9 de abril (do mesmo ano) e foi organizada por vários grupos indígenas amazônicos, os AwajunWampi tomaram o controle de uma rodovia no Norte do Peru em um lugar chamado "La Curva del Diablo". O protesto se opunha a uma série de decretos por meio dos quais o governo havia cedido seu território para a exploração de petróleo corporativa, desrespeitando o acordo I69 da OIT [Organização Internacional do Trabalho], uma legislação internacional à qual o governo peruano aderiu oficialmente, exigindo que os Estados signatários consultem e obtenham consentimento dos habitantes dos territórios que venham a ser solicitados pelas empresas para fins de exploração. Segundo os manifestantes, como a consulta não havia sido feita, a concessão não tinha legalidade. O objetivo da polícia era romper o bloqueio da rodovia, mas, devido a circunstâncias desconhecidas (que estão sob investigação), o confronto saiu de controle. De acordo com o relato oficial, o conflito conhecido como "el Baguazo" (denotando um grande evento ocorrido em Bagua) resultou em mais de 30 mortes de AwajunWampi e policiais. Duas semanas depois, no dia I9 de junho, sob enorme pressão de grupos heterogêneos, e contra a vontade do então presidente Alan García, o Congresso Nacional anulou os decretos que permitiram a concessão de territórios indígenas às empresas petrolíferas e transgrediram o acordo I69 da OIT. Ao mesmo tempo, o Estado local ordenou a prisão de alguns líderes indígenas. Aqueles que ainda estão na prisão enfrentam 33 acusações de homicídio.

Entre os detidos estava Santiago Manuín Valera, a pessoa com maior projeção pública dentre os AwajunWampi. A seguinte citação faz parte do seu testemunho durante o julgamento de Io de abril de 20I4, cinco anos após o evento. Santiago pode ficar preso para o resto da vida: 
O governo está tirando nosso território, o território do povo AwajunWampi, para que nos tornemos dependentes de sua forma de desenvolvimento. O governo nunca perguntou: vocês querem se desenvolver? Eles não nos consultaram. Respondemos: "anulem os decretos legislativos que afetam nossa existência como povo". Em vez de ouvir nossa queixa, o governo queria nos punir - outros povos se renderam, nós não. $\mathrm{O}$ governo ordenou nosso despejo forçado ${ }^{2}$.

Duas semanas após o julgamento, em 26 de abril, ele escreveu:

Nós nunca vamos aceitar que o governo faça o que quer com... o território que nossos antepassados nos legaram antes de o Estado peruano se formar. O Peru e o mundo inteiro devem saber que este lugar de 30 mil quilômetros é nosso e pertence a nós; nós sempre defenderemos e daremos nossa vida por isso. [Os AwajunWampi] estavam defendendo nosso direito, nossa identidade, nossa cultura, um modo de desenvolvimento nosso, nossa floresta, nossos rios, nosso cosmos e nosso território3.

Santiago Manuín terminou o pronunciamento declarando sua inocência. Por que seria um crime defender o território ancestral dos AwajunWampi contra um Estado usurpador? O julgamento criminal contra Manuín e outros pode ser interpretado como um conflito quanto à soberania, e, dependendo de como nos posicionarmos, podemos debater o direito dos AwajunWampi de defender seu território, ou nos aliar com a prerrogativa do Estado para decidir sobre o território nacional e o uso de recursos naturais. Levado ao tribunal, isso já seria um problema legal desafiador. No entanto, pretendo argumentar que, já no princípio do conflito, há um dissenso que não encontraria resolução dentro da lei - mesmo em sua versão mais justa - pois excede seu domínio.

Ao escrever sobre o confronto após o ocorrido, o antropólogo Shane Greene sugere "que há mais em jogo do que simplesmente uma defesa de território, um protesto contra a expansão capitalista ou uma preocupação com o destino do meio ambiente. O que também está em jogo é um modo de vida distinto"4. Explicando o confronto em meio à greve, Leni, um jovem líder de AwajunWampi - com o rosto pintado de vermelho e preto e uma bandana na cabeça -, fez pronunciamentos que exemplificam a indicação de Greene, conforme segue:

Estamos falando dos irmãos que matam nossa sede, que nos banham, que cuidam das nossas necessidades - estes [irmãos] são o que chamamos de rio. Nós não usamos o rio como esgoto; um irmão não pode esfaquear outro irmão. Nós não apunhalamos nossos

2 Pronunciamiento de Santiago Manuín contra la Petición de Cadena Perpetua Hacia su Persona. 2014. Disponível in: 〈http://www.justiciaviva.org.pe/webpanel/doc_int/doc050620I4-I44759.pdf〉. Acesso em: Ijun. 2016.

3 Ibidem (grifos meus).

4 SHANE, Greene. Making old histories new in the Peruvian Amazon. Anthropology Now, v. I, n. 3, 2009, p. 52-60. p. 58 (grifos meus). Disponível em: <www.academia.edu/649566/ Making_Old_Histories_New_in_the_Peruvian_Amazon_Bagua $\rangle$. 
irmãos. Se as corporações transnacionais se preocupassem com o nosso solo, como nós temos feito há milênios, teríamos prazer em dar espaço para que eles pudessem trabalhar aqui - mas eles se importam apenas em se beneficiar economicamente, em acumular fortuna. Não entendemos por que o governo quer arriscar nossa vida com esses decretos 5 .

Tomando a sugestão de Greene e ouvindo as palavras de Leni, quero sugerir que, nos pronunciamentos acima, "território", conforme pronunciado por Manuín, pode fazer referência tanto a um pedaço de terra sob a jurisdição do estado peruano quanto a uma entidade que emerge por meio de práticas de vida AwajunWampi, que podem, por exemplo, tornar pessoas parentes dos rios, como indica o que diz Leni. E o parentesco entre as pessoas e a água e a floresta pode transformar o próprio território em AwajunWampi, como em um recente pronunciamento público de seus líderes que disseram que "o território são os AwajunWampi".

Essa relação - em que as pessoas e o território estão juntos - excede as possibilidades dos humanos modernos e da natureza moderna, bem como as relações modernas entre eles, sem excluí-las. No entanto, isso complica o conflito: em vez de um abuso de poder que pode ser desfeito (com dificuldade, se fosse possível, é claro), o conflito se torna um mal-entendido impossível de ser resolvido sem um envolvimento nos termos que tornam o território outro em relação à capacidade de compreensão do estado e, portanto, a seu reconhecimento. Ao irromper publicamente, o conflito representa um desafio intolerável ao Estado, e a resposta a ele pode ser a erradicação de suas raízes: a negação dos termos de existência AwajunWampi. Assim visto, o conflito é ontológico. Eu me baseio em Jacques Rancière e Eduardo Viveiros de Castro para conceituá-lo como um confronto que abriga um dissenso histórico - termo de Rancière - sobre um equívoco - termo de Viveiros de Castro - sobre o que significa um território e as relações que o compõem. Juntos, esses dois conceitos, dissenso e equívoco, podem funcionar de um modo que não lhes seria possível isoladamente; seu trabalho analítico conjunto pode nos permitir refletir sobre a complexidade da disputa que os pronunciamentos de Santiago Manuín expressam. Pode ainda expor um conflito localizado tanto dentro como fora do domínio da lei.

Eduardo Viveiros de Castro é um antropólogo brasileiro; com o conceito de equívoco, ele busca explicar o modo de comunicação entre os habitantes ameríndios (humanos e não) na Amazônia brasileira. O equívoco, diz ele, abriga "a alteridade referencial entre conceitos homônimos"7 com a qual entidades que povoam mundos ameríndios se comunicam - ou se traduzem - entre si. É crucial para o conceito de equívoco o fato, em primeiro lugar, de que essas entidades - que consideramos

5 LOS SUCESOS de Bagua. Disponível em: 〈http://www.servindi.org/producciones/videos/13083 >. Acesso em: 20 jun. 2009. Citado também em DE LA CADENA, Marisol. Indigenous cosmopolitics in the Andes: conceptual reflections beyond "politics". Cultural Anthropology, v. 25, n. 2, 2010, p. 334-370.

6 PARA PERICO la territorialidad no era solo un concepto. Disponível em: $\langle$ http://www.servindi.org/actualidadnoticias-radioteca-videos/29/oI/20I6/para-perico-la-territorialidad-no-era-solo-un $\rangle$. Acesso em: 27 fev. 2016.

7 VIVEIROS DE CASTRO, Eduardo. Perspectival anthropology and the method of controlled equivocation. Tipití: Journal for the Society of Anthropology of Lowland South America, v. 2, n. I, 2004, p. 3-22. p. 4 . 
humanas ou animais - consideram-se humanas e veem seus "outros" como animais; e em segundo lugar, de que o que elas são resulta de seu ponto de vista, que, por sua vez, resulta de seu corpo. O exemplo quase canônico para ilustrar o equívoco é o das diferenças entre jaguar e humano: o que o primeiro vê como cerveja o último vê como sangue. O motivo das diferenças entre seus pontos de vista reside em seus diferentes corpos; a diferença não é conceitual, pois ambas as entidades compartilham as noções de "cerveja" e "sangue". Portanto, a comunicação, e até mesmo a preservação da vida, consiste em "controlar o equívoco" ou entender que, embora o conceito (e, portanto, a compreensão da coisa a que ele se refere) possa ser compartilhado, a própria coisa pode emergir como diferente se o conceito for proferido por alguém que é um outro para si mesmo na interlocução. Quando o equívoco é o modo de comunicação, os conceitos e as coisas estão apenas parcialmente conectados; a mesma palavra pode se referir a duas coisas diferentes, dependendo do mundo no qual é proferida. No caso que me interessa aqui, o território pode ser tanto uma porção de terra separada dos humanos e o Estado que pode ter direito a ele quanto a entidade que está com o AwajunWampi - o que define território depende do mundo que o pronuncia, das relações das quais ele emerge.

O dissenso pode ter a aparência de um equívoco. Rancière, filósofo da política e da estética, conceitua o dissenso como "o conflito entre alguém que diz branco e outro que também diz branco, mas não entende o mesmo por isso". Contudo, embora o equívoco pressuponha que todos os participantes na interlocução são falantes (podendo, portanto, nomear coisas que são conceitualmente as mesmas e "objetivamente" diferentes), o mal-entendido que provoca o dissenso (à la Rancière) resulta de "uma disputa sobre o que significa falar"; "uma disputa quanto ao objeto da discussão e quanto à capacidade daqueles que fazem disso um objeto". Além disso, como uma interrupção política que altera a ordem convencional e estabelece discordância quanto à igualdade, trata-se de uma disputa que confronta aqueles que têm (aos quais se concede a capacidade de) discurso com aqueles que não têm (aos quais é negada a capacidade de) discurso - é uma disputa sobre as convenções que distribuem capacidades para definir o que é e como é. As lutas por direitos civis nas Américas seriam um exemplo de como o dissenso estabeleceu uma nova ordem do perceptível. Assim, eis a diferença entre tais conceitos: o equívoco é um mal-entendido em uma relação entre iguais que são (ou seja, em termos ontológicos) mutuamente outros.

O mal-entendido é uma relação ontológica; embora o equívoco possa ser discernido (ou controlado, como diz Viveiros de Castro), ele também é uma condição inevitável que não pode ser alterada. Em vez disso, o dissenso coloca indivíduos socialmente desiguais em uma disputa para serem os mesmos (ou socialmente equivalentes), e a partir dessa posição nomear e definir o que deveria ser o mesmo; aqui o mal-entendido é político e reflete uma disputa epistêmica para mudar como a ordem estabelecida é percebida. Dito de forma diferente e talvez mais clara nos termos do argumento deste artigo: o mal-entendido no equívoco emerge quando corpos que pertencem

8 RANCIÈRE, Jacques. Disagreement: politics and philosophy. Minneapolis: University of Minnesota Press, I999, p. xii

9 Ibidem, p. x, xi, xii. 
a mundos diferentes usam a mesma palavra e nomeiam entidades que não são as mesmas porque elas também, como os corpos que as nomeiam, pertencem a mundos diferentes; o dissenso resulta de mal-entendidos sobre condições de nomeação das mesmas entidades em um mundo que deve ser compartilhado.

\section{Política impossível, GUERRA SILENCIOSA E O “ANTROPO-CEgo"}

Pensando na noção de dissenso de Rancière, o "grande evento em Bagua" pode ser traduzido como a irrupção da política: um evento histórico em que surge um sujeito que perturba a distribuição do discurso e da ordem que ela cria. No dissenso, esse sujeito irrompe na ordem estabelecida (onde ela ou ele não têm fala) para propor outra distribuição das vozes, ouvidos, mãos e, finalmente, corpos que denominam o que o filósofo francês chama de perceptível. No caso específico de El Baguazo, o dissenso que os AwajunWampi manifestaram teria interrompido a distribuição do discurso que atribui ao Estado a soberania para decidir sobre o território. Contra isso, os AwajunWampi teriam reivindicado sua própria voz soberana. Entendida como uma extensão do país sobre a qual os humanos têm poder de decisão, a entidade "território" teria permanecido a mesma: o que a define - e de que modo - não estaria sob disputa.

Em vez disso, conceituado como um dissenso que abriga um equívoco, o conflito também pode ser interpretado como uma disputa em torno de uma entidade - o território - que não é a mesma coisa e não pode ser as coisas diferentes que podem surgir nas interlocuções entre os AwajunWampi e o Estado. Pensando em "território" como equívoco, os pronunciamentos de Santiago Manuín - e o julgamento do qual emergem - também refletiriam um dissenso de natureza ontológica. Assim, o equívoco também seria uma disputa política agravada pela condição de sua impossibilidade, pois nem o Estado nem a lei são capazes - e muito menos equipados - para reconhecer o equívoco ou a disputa política em torno dela. Chamo essa condição de antropo-cego. Conceitualizo-a como o processo de criação de mundo por meio do qual mundos heterogêneos que não se fazem por meio de práticas que separam ontologicamente os humanos (ou a cultura) dos não humanos (ou a natureza) - nem necessariamente concebem como tal as diferentes entidades presentes em seus agenciamentos - são ambos obrigados a operar com essa distinção (deliberadamente destruída) e excedê-la. O antropo-cego seria, portanto, tanto a vontade que coloca a distinção como obrigação (e destrói aquilo que desobedece a obrigação) quanto o fato de que ela é excedida: os coletivos que, como o AwajunWampi, são compostos por entidades que não são apenas humanas ou não humanas, porque elas também compõem com aquilo que (de acordo com a obrigação imposta) não devem ser: humanos compondo com não humanos, $\mathrm{e}$ vice-versa.

No âmbito acadêmico, o Antropoceno faz referência à era em que os humanos se tornaram uma força geológica capaz de destruição planetária. O antropo-cego faz uma óbvia referência ao termo, e o sufixo é igualmente óbvio, chamando atenção para o ceno. No entanto, o "cego" pode ser enganador, pois, ao usá-lo, minha intenção não é evocar a suposta dimensão invisível que suportaria a coação do poder sob 
um domínio visível. Na verdade, o "cego" não se refere propriamente a um regime de visibilidade. Em vez disso, o termo quer fazer referência a algo inerente a uma condição de impossibilidade hegemônica formulada historicamente, indicando que parceiros antagonistas e suas relações antagônicas estão incluídas no antropo-cego.

Por um lado, o antropo-cego compreende as práticas e os praticantes da vontade que concedeu a si própria o poder de erradicar todos os seres desobedientes para que se adaptem ao "humano" conforme sancionado pela modernidade (nas versões inicial e tardia). Por outro lado, inclui os praticantes desobedientes de coletivos compostos com entidades insubmissas à classificação (e individuação) como humanas ou não humanas. De um modo complexo, o antropo-cego inclui tanto o antropos "que anda ereto" ${ }^{\text {ז0 }}$, incorporando a vontade autoconcedida de transformar o mundo naquilo que ele ou ela conhecem, e o antropos desobediente, aquele que inerentemente compõe com os outros e é, portanto, não apenas humano. Ambos habitam a dimensão do "cego", mas eles o fazem em uma relação de antagonismo: no caso do antropos de andar ereto, o "cego" (como tal) é a sua vontade constitutiva de destruição que, por sua vez, anula a possibilidade de desobediência por parte dos seres e, portanto, torna a sua condição "cega". Como um processo organizado de destruição - às vezes por meio de uma assimilação oferecida benevolentemente -, o antropo-cego incluiu e continua a incluir uma guerra silenciosa travada contra entidades e práticas mundiais que ignoram a separação de entidades em natureza e cultura ${ }^{\text {II }}$.

Datando desde o início do século XVI no que se tornaram as Américas, a guerra se deu inicialmente em alto e bom som; lutando por seu deus, os clérigos cristãos andaram pelos Andes da Colômbia até a Argentina e o Chile, "extirpando idolatrias", uma prática política que os frades criaram contra o "culto induzido pelo demônio". A extirpação exigia dividir as entidades participantes em uma natureza feita de Deus (montanhas, rios, florestas) e naturales, ou seja, humanos incipientes com uma alma ainda a ser salva. A invenção da política moderna secularizou o antagonismo: a guerra contra a insubmissão quanto à distinção entre Natureza e Humanidade foi silenciada; mas continuou em nome do progresso e contra o atraso, o mal que substituiu o Diabo. Dada a sua vocação hegemônica, as práticas de guerra incluíam formas de produção de vida. Os humanos inferiores se tornaram objeto de inclusão benevolente e inevitável, inimigos que nem sequer contavam como inimigos: a guerra foi travada por meios silenciosos. Esta última frase parafraseia a inversão proposta por Foucault para o aforismo clássico de von Clausewitz (a guerra é uma continuação da política por outros meios): "a política é a continuação da guerra por outros meios" Com a frase, ele explica, primeiro, que as relações de força por meio das quais o poder moderno opera foram estabelecidas dentro e por meio da guerra em um determinado

Io HARAWAY, Donna. Anthropocene, Capitalocene, Plantationocene, Chthulucene: Making Kin. Environmental Humanities, v. 6, 20I5, p. I59-I65.

II De modo similar, Latour conceitualiza essas guerras como "latentes", "nunca declaradas", "consideradas simples operações de polícia”. LATOUR, Bruno. War of the worlds. What about peace?. Trad. Charlotte Bigg. Chicago: Prickly Paradigm Press, 2002.

I2 FOUCAULT, Michel. Society must be defended. Lectures at the Collège de France, I975-I976. Trad. David Macey. New York: Picador, 2003, p. I5. 
momento histórico; em segundo lugar, que, embora a política "pacifique", certamente não o faz por meio de uma neutralização de desequilíbrio proporcionada por uma batalha final, mas, em vez disso, e em terceiro lugar, "o papel do poder político é usar perpetuamente uma espécie de guerra silenciosa para reinscrever essa relação de força, inscrevendo-a em instituições, desigualdades econômicas, na linguagem e até mesmo no corpo dos indivíduos"³. Trago Foucault para indicar, em primeiro lugar, que a marca da guerra que estabeleceu o poder moderno foi a sua vontade colonial de destruir - ou assimilar aquilo que equivale à destruição, mas ainda assim tem potencial hegemônico - tudo o que não era a sua imagem e semelhança; em segundo lugar, para chamar atenção para o fato de que o que entendemos por "batalha final" está sempre em curso e, finalmente, em terceiro lugar, que, em vez de ser travada através da política, a guerra moderna pode ser um mecanismo contra a demanda por políticas colocadas por esses coletivos contra os quais a guerra se desenrola ${ }^{\mathrm{I}}$. Quando esses coletivos representam essa demanda - quando o dissenso em torno dos equívocos se torna público e os coletivos pressionam em busca de um reconhecimento que o Estado não concede -, a guerra silenciosa pode se traduzir em uma batalha aberta, travada pelo Estado em nome do bem comum; os coletivos desobedientes reagem para defender sua sobrevivência.

\section{O EXTRATIVISMO OU O FIM DA GUERRA SILENCIOSA (E DO ANTROPO-CEGO)}

O "extrativismo" é um conceito que circula bastante profusamente na América Latina e que, literalmente, torna o Antropoceno presente materialmente como uma força geológico-humana, ao mesmo tempo que coloca em primeiro plano sua articulação por meio do capital financeiro e em conexão com o crescimento infraestrutural. Algumas das principais discussões do termo, utilizado em círculos ambientais na região, observam que ele remete ao início das práticas extrativistas da mineração colonial espanhola ${ }^{15}$. A extração de prata do Cerro Rico de Potosí e Huancavelica (atualmente Bolívia e Peru) são exemplos abomináveis de morte e destruição causados pela extração de minerais para circulação nos mercados metropolitanos ibéricos. As plantações de guano, borracha, algodão e açúcar e a perfuração para fins de exploração de petróleo (principalmente em áreas costeiras com acesso a pequenos portos) se deram no final do século XIX. Em seguida, viabilizado pela construção de ferrovias, o crescimento dos portos em tamanho e número, bem como com a criação

I3 Ibidem, p. I6.

I4 Foucault mais uma vez: “o papel do poder político é usar perpetuamente uma espécie de guerra silenciosa para reinscrever essa relação de força e reintegrá-la nas instituições, nas desigualdades econômicas, na linguagem e até mesmo nos corpos de indivíduos”. Ibidem, p. I5.

I5 GUDYNAS, Eduardo. Extractivismos. Ecología, economía y política de un modo de entender el desarrollo y la naturaleza. La Paz: Cedib, 20I5; BEBBINGTON, Anthony. Political ecologies of resource extraction: agendas pendientes. Revista Europea de Estudios Latinoamericanos y del Caribe, n. I00, 20I5, p. 85-98; SVAMPA, Maristella. Commodities consensus: neoextractivism and enclosure of the commons in Latin America. The South Atlantic Quarterly, v. II4, n. I, 20I5, p. 65-82. 
de uma indústria naval mercante, um grande número de minas foram abertas ao longo do século XX, atraindo capital dos EUA e da Inglaterra. Conjuntamente, essas atividades contribuíram para um aumento geral da renda nacional, para a "transformação" ecológica e para a morte das populações (desnecessário dizer que estas eram na sua maioria compostas por indígenas e escravos de origem africana).

Muitas características tornam o "extrativismo" um empreendimento diferente das práticas anteriores (também extrativas). Alguns aspectos óbvios são o caráter corporativo da prática, a ubiquidade mundial e a interconectividade do modelo, a taxa de expansão sem precedentes dos mercados de minerais, petróleo e energia e a magnitude das novas tecnologias que permitem uma extração rápida e lucrativa.

A antiga "mineração de túnel" - designação pela qual se tornou conhecida a perfuração de montanhas seguindo a veia de minerais - foi substituída por "poços abertos" que destroem montanhas, criando formações de crateras que se estendem por cima de centenas de hectares e atingem profundidades de mais de mil metros ${ }^{16}$. As plataformas de múltiplos poços aumentaram substancialmente a proporção de barris e a velocidade de produção, e tecnologias relativamente novas, como o fraturamento terrestre e em zona de transição terra-mar e a produção de petróleo a partir de areias betuminosas, são responsáveis pela expansão territorial sem precedentes da extração de petróleo. A magnitude dos chamados "impactos ambientais" também não tem precedentes. Um exemplo: entre os anos de 2006 e 20II, a Bolívia produziu 5600 toneladas de prata, o que exigiu a remoção de mais de 44 milhões de toneladas de rochas (remover as rochas de onde estavam e depois despejá-las em outros lugares também traz destruição). E embora as imensas quantidades de água usadas na mineração não sejam exatamente destruídas, tornam-se tão cheias de contaminantes que ficam inúteis para o consumo de qualquer ser vivo. No caso do petróleo: o fraturamento usa quantidades extraordinárias de água, libera grandes volumes de resíduos tóxicos e radioativos e poluentes perigosos do ar e afeta corpos de todo tipo em vastas áreas ${ }^{17}$. As plantações de palmeiras de soja e óleo (entre outros) se juntam à produção do que o biólogo e político uruguaio Eduardo Gudynas chamou de "amputações ecológicas" ${ }^{8}$. A construção de infraestrutura (necessária para comercializar os recursos) patrocinada por instituições financeiras centrais como o FMI [Fundo Monetário Internacional], o Banco Mundial e novas entidades financeiras regionais, como o Banco Latino-americano de Desenvolvimento, permite que a extração atinja territórios remotos. Tudo isso impulsiona o que parece ser uma

I6 Por exemplo, Chuquicamata, uma mina de cobre no Chile, estende-se por mais de 800 hectares e tem I.250 metros de profundidade. Ver: GUDYNAS, Eduardo, op. cit.

I7 Uma das maiores ameaças atuais de fraturamento na América do Sul está localizada na região de Entre Ríos, na Argentina, e na área vizinha, no Chaco do Paraná, no Uruguai, onde está prevista a extração de petróleo de xisto e gás de xisto. Ver: NAVARRO, Santiago; BESSI, Renata. Fracking Expands in Latin America, Threatening to Contaminate World's Third-Largest Aquifer. December II, 20I5. Disponível em: <https://www.alternet.org/ fracking/fracking-expands-latin-america-threatening-contaminate-worlds-third-largest-aquifer $>$. Acesso em: 24 jan. 2018.

I8 GUDYNAS, Eduardo, op. cit. 
remoção sem precedentes, irrefreável e poderosa de recursos nesses territórios, visto que também são transformados em espaços para investimentos financeiros.

O extrativismo, por mais que possa trazer preocupações ecológicas imensas, tornou-se um componente central das estratégias econômicas de todos os governos da região, esquerda e direita e sem exceção. Talvez a única diferença seja que, enquanto os primeiros declaram que preferem executar a própria extração, os últimos abriram seus territórios de forma decidida para empresas transnacionais. "Apropriação pela poluição" é o título que Michel Serres ${ }^{\text {I9 }}$ dá ao pequeno livro em que ele discute a crise ecológica planetária com a qual vivemos - poluir é possuir, é excluir os outros do acesso aos recursos de que o poluidor se apropria.

E, é claro, a apropriação por meio da poluição também mata os humanos que o antropos não se importa em ver - e que, portanto, não importam, às vezes, as amputações ecológicas, incluindo as mortes humanas, consideradas "geografias do sacrifício" ${ }^{\circ 0}$ necessárias, para adotar a frase de Valerie Kuletz e adaptá-la ao ethos do extrativismo de acordo com as formas de vida que continuam a existir nos espaços de que obtêm recursos, descartáveis porque deveriam ter desaparecido há muito tempo. Movido por uma corrida bem financiada pelo progresso e promovido pelo crescimento econômico, o alcance da atual destruição dos mundos indígenas é historicamente incomparável, e as notícias sobre isso não são escassas; não é preciso esforço para tomar conhecimento de incidentes terríveis em qualquer momento. Vejamos este comentário publicado em 23 de março de 20I6, enquanto eu estava escrevendo este texto: ele narra a lenta morte de um grupo indígena reconhecido na Colômbia como os Wajúu, que sofriam com uma mina de carvão tristemente célebre:

Tudo lhes foi tirado. Roubaram-lhes as terras, as águas, até os nomes. [...] E a espoliação continua. O que os queima de sede não é o capricho da natureza, nem uma consequência do aquecimento global: é essa grande empresa de carvão de El Cerrejón que construiu a represa El Cercado, que o Estado inaugurou com grande publicidade e sugou a água para a necessidades da imensa mina. A mina cresce, e, conforme cresce, empurra os Wayúus para o deserto em La Guajira. [Antes da barragem] El Cerrejón já havia desviado para seus próprios fins o curso de vários riachos que alimentavam o Rio Ranchería, e agora insiste em construir um novo leito, levando assim todo o rio para alcançar os imensos depósitos de carvão que ficam debaixo da água ${ }^{2 I}$.

Denúncias como as anteriores encontram um público além dos povos indígenas cuja vida está em jogo e entre aqueles mais geralmente preocupados com a distribuição de conflitos ecológicos e direitos humanos. Escavar uma montanha para abrir uma mina, perfurar o subsolo para encontrar petróleo, represar todos os

I9 MICHEL, Serres. Malfeasance. Appropriation through pollution?. Stanford: Stanford University Press, 20 II.

20 VALERIE, Kuletz. The tainted desert: environmental and social ruin in the American West. New York: Routledge, I998.

2I CABALLERO, Antonio. Mil palabras por una imagen. Miseria artificial. Arcadia, 20I6. Disponível em: <http:// www.revistaarcadia.com/opinion/columnas/articulo/antonio-caballero-escribe-sobre-la-guajira-y-saqueo-a-losindigenas-wayuu/47708>. 
rios possíveis e arrasar árvores para construir estradas transoceânicas e ferrovias são ferramentas para a transformação de territórios em investimentos, mas é difícil conquistar a hegemonia desses locais. O extrativismo se deparou com uma oposição implacável que articula, de maneira complexa e irregular, alianças inesperadas em demandas heterogêneas de uma vasta gama de coletivos. Centralmente e em toda a sua complexidade diversa, a aliança desafia o monopólio do Estado e das corporações a criar, habitar e definir a natureza - e, às vezes, o desafio que ela representa toca os nervos dos estados que produzem o sentimento de que a soberania sobre os territórios que governam é desafiada, e que suas esperanças de crescimento econômico (colocadas sobre o extrativismo) são comprometidas. Até agora, a reação dos estados nacionais (da esquerda e da direita) tem sido vacilar entre aceitar ou rejeitar as demandas de negociação de seus oponentes. Quando a rejeição acontece, o que eu chamo de "guerra silenciosa" se dá em um campo de batalha aberto - em nome do progresso, como sempre. O confronto ocorrido em 2009 na "Curva del Diablo" é emblemático do fim da guerra silenciosa: aqueles que se opõem à transformação da natureza universal em recursos se opõem à possibilidade do bem comum como missão do Estado-nação e, assim, são inimigos do Estado, merecendo no mínimo ser presos.

A aliança contra o extrativismo é complexa. Sendo politicamente relevante, ela tem capacidade de atrair atenção pública contra a participação do Estado em violações de direitos humanos e amputações ecológicas por parte de corporações; ao mesmo tempo, por meio de noções modernas (ambiente, direitos e biodiversidade), as práticas de construção da realidade da aliança continuam a ser próprias do antropo-cego. No entanto, a complexidade não termina aqui - e, seguindo isso, podemos achar que a aliança merece atenção. Defendendo-se, os porta-vozes dos mundos que experimentavam a destruição - dessa vez nas mãos do extrativismo - expuseram as práticas dos extrativistas por meio de estações de televisão e jornais. Desafiando a legitimidade da vontade de destruir, eles mostraram que essa natureza ou meio ambiente - assunto de interesse público - não se resume a isso. As revelações de seres inimagináveis e de sua destruição podem ser tão onipresentes quanto a guerra contra aqueles que se opõem ao que o Estado considera (pelo menos até o momento) como a missão de providenciar o bem comum. O mundo único que o cristianismo e a modernidade construíram e sustentaram de forma conjunta está sendo desafiado - talvez de modo sem precedentes desde sua inauguração, há 500 anos. Proponho aqui que o momento em que o antropo-cego, como a destruição dos mundos, parece ter adquirido um poder e uma velocidade que os primeiros extirpadores de idolatrias e exploradores do século XIX (investidores de borracha e plantação de açúcar) invejariam também é o momento em que, do outro lado da cerca - do antropo-cego como a rejeição dos mundos à sua destruição -, emergem histórias que podem trazer à tona um público que ainda não existe ${ }^{22}$. Assim, mesmo que o que se torne público seja uma tradução para as preocupações ambientais e de direitos humanos, as denúncias e as alianças que as tornam possíveis, isso oferece uma possibilidade de abertura ontológica que merece atenção.

22 MICHAEL, Warner. Publics and counterpublics. Brooklyn: Zone Books, 2005. 


\section{Histórias do anTROPO-CEgo}

[...] nós precisamos de histórias (e teorias) amplas o suficiente para reunir as complexidades e manter as fronteiras abertas e insaciáveis por novas e surpreendentes conexões[... $]^{23}$

Analogamente à alegação dos AwajunWampi quanto a serem seus territórios ancestrais e a afirmação de seu parentesco com a floresta, um grupo mapuche escreveu o seguinte em um comunicado em uma disputa sobre extração de petróleo em um site chamado Vaca Muerta (Argentina): “Nossos territórios não são 'recursos', mas vidas que fazem o Ixofijmogen do qual somos parte, e não proprietários”24. Por outro lado, é assim que a Vaca Muerta é definida por desenvolvedores de Neuquén, um dos estados incluídos no depósito de hidrocarbonetos em questão: "Vaca Muerta é um deserto imenso [a Estratega estéril e estéril]. Um deserto que se estende além do que os olhos podem ver [...]. É um território hostil que abriga energia suficiente para tornar o argentino autossuficiente e até exportar gás e petróleo para o mundo". $\mathrm{O}$ alto contraste entre esses pronunciamentos sugere que a disputa do público não trata apenas sobre a extração de petróleo. O pronunciamento mapuche revela a relacionalidade inerente entre as entidades que compõem Ixofijmogen, que, portanto, não podem ser facilmente divididas em território e os recursos extraídos dela. O que a empresa petrolífera decreta como natureza e humanos, os mapuches não são apenas promulgados como tal ${ }^{25}$. A interrupção da partição hegemônica é um evento político mundial que também é conceitual: realiza uma abertura ontológica naquela partição que possibilita a promulgação dos seres humanos com a natureza. Essa condição (que não é simplesmente uma mistura de seres humanos $e$ natureza) torna cada um dos outros mais do que apenas um deles. Além disso, as entidades podem emergir como materialmente específicas para a (e por meio da) relação que as liga intrinsecamente. Um exemplo do meu próprio trabalho nos Andes do Cuzco: runakuna (a palavra quéchua local para as pessoas) com tirakuna (entidades que também são, ainda que não apenas, montanhas) estão juntas em complexidade de materialidade e vivacidade, enquanto fabricam em conjunto o local e são fabricados

23 HARAWAY, Donna, op. cit., p. I60.

24 VACA Muerta: “Una situación urgente que no da para más”. Disponível em: <http://www.argenpress. info/20I4/Io/vaca-muerta-una-situacion-urgente-que.html>. Acesso em: 24 jan. 20I8; UN VIAJE a las entraNas de Vaca Muerta, El Futuro energetico del país. Disponível em: <http://misionesonline.net/20I5/03/o7/unviaje-a-las-entranas-de-vaca-muerta-el-futuro-energetico-del-pais/>. Acesso em: 6 jul. 2015.

25 Expliquei isso em outros trabalhos. Habitar em mais do um e menos do que em muitas práticas de mundo pode promulgar entidades “não apenas": seres diferentes dos humanos emergem não só como tal, mas também como natureza e seres humanos. John Law chama isso de capacidade para ambos/e (em vez de ou/ou). Ver: DE LA CADENA, Marisol. Earth beings: ecologies of practice across Andean worlds. Durham: Duke University Press, 20I5; DE LA CADENA, Marisol, 20Io, op. cit.; LAW, John. After Method: Mess in Social Science Research. New York: Routledge, 2004. 
por ele ${ }^{26}$; em contraste, a materialidade e a relação entre humanos vivos modernos $e$ montanhas inertes os distinguem um do outro.

Runakuna com seres terrestres não são, é claro, um requisito dos processos que surgiram para questionar a universalidade da partição do sensível na natureza e nos seres humanos. Eis outro exemplo: no norte dos Andes do Peru, uma empresa de mineração planeja drenar várias lagoas para extrair cobre e ouro de alguns e drenar resíduos minerais em outros. Em troca, reservatórios com capacidade de água várias vezes a das lagoas seriam construídos. Em contraposição ao plano, os ambientalistas argumentam que os reservatórios destruirão o ecossistema do qual as lagoas fazem parte: uma paisagem de terras agrícolas, zonas úmidas de alta altitude, gado, humanos, árvores, culturas, riachos e nascentes. A população local acrescenta que as lagoas são a vida local: suas plantas, animais, solos, árvores e famílias estão com aquela água específica que não pode ser traduzida em água de reservatórios, nem mesmo se, como promete a empresa de mineração, proporcionassem mais água. Não seria a mesma água; para defendê-lo, eles se organizaram como "guardiões das lagoas". Muitos guardiões morreram nessa defesa, tornando público outro exemplo da guerra contra aqueles que se opõem à tradução da natureza em recursos. No entanto, os guardiões das lagoas nunca disseram que a água é um ser; o que eles dizem é que é água local: a água com a qual eles, suas plantas, seus animais e, finalmente, "suas naturezas" são. Como tal, é intraduzível para $\mathrm{H}_{2} \mathrm{O}$ e não pode ser usada para o bem comum geral. Em vez disso, passando por órgãos locais (humanos e outros que humanos), por meio da prática política de seus guardiões, a água dessas lagoas emerge, pois coloca as entidades e se torna uma natureza incomum, ou a natureza já ocupada por órgãos locais e, portanto, não está disponível para transformação no interesse do Estado ou da empresa se eles não coincidirem com os de seus corpos.

Essa água da lagoa - e a "natureza" ela constitui-é um objeto de fronteira complexa nesse conflito. De um lado, a natureza é metade de um dualismo; por outro lado, abrangendo heterogeneidades humanas e outras-que-humanas [other-than-human], a natureza é um termo quase sem sentido. Complexamente, então, a água da lagoa não é apenas natural, e a natureza não é apenas a Natureza ${ }^{27}$. A política que ela - a água da lagoa - propõe é igualmente complexa e evasiva para o tipo de análise ou análise que requerem um acordo ontológico sobre o que é.

Uma icônica "guardiã das lagoas" é uma mulher camponesa cujas terras o projeto de mineração corporativa quer comprar para legalizar completamente seu acesso aos territórios que planeja escavar. A mulher, cujo nome é Máxima, se recusa a vender - e provavelmente por uma quantia de dinheiro que ela nunca veria em sua vida. Inúmeras vezes, a força policial nacional, contratada pela mineradora, destruiu as colheitas da família, atacou ela e seus filhos, até seus animais; influenciados pela

26 DE LA CADENA, Marisol, 20I5, op. cit.; DE LA CADENA, Marisol, 20Io, op. cit.; DE LA CADENA, Marisol. Human but not only. HAU: Journal of Ethnographic Theory, v. 4, n. 2, 20I4, p. 253-259.

27 "Objeto fronteiriço" é um termo cunhado por Star e Griesemer em I989. STAR, Susan Leigh; GRIESEMER, James R. Institutional ecology, translations and boundary objects: amateurs and professionals in Berkeley's Museum of Vertebrate Zoology, I907-39. Social Studies of Science, v. I9, n. 3, I989, p. 387-420. Agradeço a Judy Farquhar por conversas que alimentaram esse parágrafo. 
mineradora, vários tribunais judiciais decidiram contra a mulher. Ela também ganhou algumas batalhas legais: quando escrevi esta peça, um tribunal judiciário ordenou que a polícia nacional protegesse a mulher e sua família da mina. As terras da mulher estavam sob cerco havia mais de três anos. "Eu luto para proteger a lagoa" foi uma das suas respostas. E afirmando o apego ao lugar, ela acrescentou: "Eu não vou parar; eles podem acabar comigo. Mas vou morrer com a terra".

Sua recusa em vender é incompreensível para a racionalidade dominante orientada para o mercado. Também pode nos fazer lembrar semelhanças entre Máxima e Bartleby, o escrivão na história de Melville, cuja recusa em fazer como lhe é solicitado por aqueles que o rodeiam provocou inúmeras reflexões filosóficas ${ }^{28}$. Bartleby diz que ele "prefere não" fazer o que seus superiores pedem para ele fazer. Porque os pedidos parecem lógicos, e como o escrivão não explica por que ele "prefere não" fazer, deixa seus superiores loucos. Da mesma forma, a recusa de Máxima em vender deixou os funcionários da mineradora loucos: ela impede a mineração de cumprir seu objetivo. No entanto, ela não é necessariamente agramatical, pelo menos não no sentido de desvinculação do social que Deleuze concede à agramaticalidade ${ }^{29}$ de Bartleby.

Por meio da lente da política moderna (e usando a gramática que separa os seres humanos e a natureza universal), podemos interpretar as ações dessa mulher como defendendo o ecossistema: um ambientalista e, portanto, um inimigo ou um aliado, dependendo de quem fala. Impulsionados pela exasperação, os adeptos dos reservatórios (e também os políticos "racionais") a veem como um manipulador esperto que aguarda um preço melhor por sua terra ${ }^{30}$; para aqueles do outro lado do espectro político - a complexidade que vou explicar e na qual me incluo - ela é um herói disposto a se sacrificar para evitar danos ecológicos. Na linguagem de ambos, detratores e adeptos, ela é um sujeito em relação a um objeto - e, portanto, perfeitamente gramatical enquanto atua em resposta às condições que lhe são impostas. No entanto, a "recusa de venda" pode incluir outra relação: uma de onde mulher-terra-lagoa (ou plantas-pedras-solos-animais-lagoas-humanos-canaiscalhas!!!) emergem inerentemente juntas - um emaranhamento de entidades necessitadas umas das outras, de tal forma que separá-las as transformaria em outra coisa $^{31}$.

28 HARVEY, Penelope; KNOX, Hannah. Roads. An anthropology of infrastructure and expertise. Ithaca: Cornell University Press, 2015.

29 DELEUZE, Gilles. Bartleby; or the Formula. In: Essays critical and clinical. New York: Verso Books, I998, p. 68-9I.

30 Ver: EL PANTANOSO caso Chaupe. Disponível em: <http://larepublica.pe/politica/858259-el-pantanoso-casochaupe $>$. Acesso em: 24 jan. 2018.

3I Outro exemplo de uma materialidade relacional similar: os camponeses do Istmo de Juchitán (Oaxaca, México) rejeitaram a instalação de moinhos de vento que transformariam a relação entre ar, pássaros, água do oceano, peixes e pessoas. Ver: HOWE, Cymene; BOYER, Dominic; BARRERA, Edith. Wind at the margins of the state: autonomy and renewable energy development in Southern Mexico. In: MCNEISH, John-Andrew; BORCHGREVINK, Axel; LOGAN, Owen (Org.). Contested powers. The politics of energy and development in Latin America. London: Zed Books, 2015. 
A recusa de venda também pode recusar a gramática que transforma as entidades em corpos individuais, unidades da natureza ou do meio ambiente, que, quando são parte uns dos outros, não são. Assim analisado, a recusa de Máxima seria o ato de um pensador particular, aquele que pensa com suas próprias forças para promulgar uma natureza ecologizada localmente (entidades interdependentes umas das outras) que simultaneamente coincide, difere e até ultrapassa (também porque inclui humanos) o objeto de que o Estado, a empresa de mineração $e$ os ambientalistas se traduzem em recursos, exploráveis ou a serem defendidos ${ }^{32}$. Construindo "um tipo de linguagem estrangeira dentro da linguagem" ${ }^{33}$, ela também se torna agramatical no que diz respeito à relação entre sujeito e objeto e ao social que disso decorre. Sua resposta é impulsionada por uma lógica que excede a do lucro e do ganho, e a do meio ambiente e de sua defesa. Nesse sentido, a resposta de Máxima pode ser como a fórmula de Bartleby proposta por Deleuze: uma resposta que excede qualquer lógica conhecida ou esperada, que possa confundir qualquer posição social atribuída, ao mesmo tempo que se autoafirmam posições compostas que se comunicam com as gramáticas usuais e, ao mesmo tempo, abre-os para outras possibilidades.

Se ela é ambientalista - e eu acho que ela é - ela não é apenas uma ambientalista. Defendendo a si mesma, e também indo além de si mesma, ela declara sua administração de lagoas e tudo o que suas águas são e permitem, e ela faz isso de mais de uma maneira. Ela confronta a mineradora argumentando sua propriedade sobre a terra - ela ainda mostra os documentos legais que provam sua propriedade. No entanto, quando Máxima explica como é impossível haver uma separação em seu estar-com-a-terra, como elas estão juntas, como compõem com as culturas, chuva, solo, animais - entidades que fazem/são a relação - sua explicação, proponho, excede o limite do conceito de propriedade, no que ela, no entanto, também considera a mineradora em seu confronto. Ela fica porque está por ficar; que isso lê como uma redundância marca a agramaticalidade da decisão da mulher. Quando perguntei por que ela ficou (como muitos outros fizeram antes de mim e, tenho certeza, depois) ela respondeu: "O que posso ser se não sou isso? [E a palavra "lugar" não é proferida - em vez disso, os pés estão pisoteados.] Isto é quem eu sou, como posso ir? Eu morreria [a palavra 'aqui' não é pronunciada] quem eu sou, com os meus ossos que irei [uma vez mais 'aqui' não é pronunciado] como eu sou agora". É claro que podemos ler suas palavras como um assunto habitual e gramática de objetos - que eu sugeri com as palavras entre parênteses; mas a necessidade dos parênteses - as não declarações nas respostas de Máxima não são "espaços em branco a serem preenchidos" - também sugere que não há apenas uma gramática para sua recusa em vender a terra que a mineradora quer. Como não precisamos de ajuda com nossos hábitos, chamo atenção para o incomum.

Não apenas é uma expressão que nós (acadêmicos ou não) costumamos usar em nossas análises - eu mesma já a utilizei em vários parágrafos anteriores. Aprendi a dar um status conceitual a essa expressão a partir de conversas com Mariano Turpo, um amigo com quem colaborei na elaboração das ideias que entraram em um livro

32 Cf. DELEUZE, Gilles; GUATTARI, Felix. What is philosophy?. New York: Columbia University Press, I994.

33 DELEUZE, Gilles, I998, op. cit. 
que publiquei não muito tempo atrás ${ }^{34}$. Falante de quéchua e um transeunte entre alguns dos mundos que constituem nosso país (Peru) -, ele insistia que o que para mim era (algo que para mim, por exemplo, era uma montanha ou um arquivo) não era apenas isso. E eu só consegui compreender o significado disso quando isso se tornou não apenas isso para mim - ou, até que por meio de uma prática laboriosa e paciente, pude transformar meu pensamento, afastando-me do hábito de precisar entender (muitas vezes mal) a entidade ou a prática em questão. Captar o que era "não só" o que me vinha por meio da minha prática habitual de pensamento, além de levar tempo, exigiu trabalhar em uma interface permanente, na qual as práticas de produção de mundo de Mariano e as minhas eram aparentemente parecidas e, ao mesmo tempo, diferentes ${ }^{35}$. E o que surgiu na interface em vez de "a" entidade ou prática em questão foi uma "redescrição" mútua dos conceitos, formas ou figuras do outro (de Mariano e minha) de maneira que sempre se excediam, mesmo que também se sobrepusessem ${ }^{36}$. A partir dessa experiência etnográfico-conceitual, proponho pensar que a recusa de Máxima em deixar à luz da noção de propriedade (e suas relações) também por meio do que pode ser não apenas propriedade e as relações (ou a falta delas) que podem emergir para fazê-la (com-aqueles-com-os-quais-ela-é.) Ao considerarmos ambas as relações simultaneamente, seus excessos mútuos também podem ser considerados. Explico mais detidamente a seguir.

Os conceitos fazem seu trabalho em uma ecologia. Eles agem junto com os conceitos dos quais estão acompanhados ${ }^{37}$ - e quando Máxima pratica sua recusa de sair, "propriedade" pode emergir como um conceito múltiplo, pois ela passa de tornar-se com a "terra" para se defender legalmente em relação à tentativa da corporação de expulsá-la. "Tornar-se com a terra” excede a noção legal de propriedade e emerge no seu limite (ou seja, quando o conceito legal não é mais). "Recusar-se de sair” pode ser motivado por uma rejeição ideológica ao desejo da mina de destruir lagoas, e também pode ser uma prática que desafia a comensuração, tornando a terra "inocupável" pelo mercado, pois é integralmente ocupada por e ocupa "a mulher que não vai sair”. Essa última frase - que circula principalmente em comentários orais - indica o desafio inconcebível que Máxima impõe à mina, e também pode traduzir sua agramaticalidade: a promulgação de uma relação que a propriedade moderna não tem como sustentar. Isso incluiria sua capacidade de se transformar com o coletivo: os guardiões humanos das lagoas, mas também as entidades que não são humanas que elas protegem. Intrigantemente, seu advogado - também uma mulher e familiarizada com as práticas dos "guardiões da lagoa" - entende isso, e com isso, sua própria impossibilidade de traduzir plenamente a insistência de Máxima em permanecer para a linguagem legal da propriedade. Em uma das muitas entrevistas que Máxima deu, ela menciona que um "homem-empresa", "un hombre de la compañía",

34 DE LA CADENA, Marisol, 20I5, op. cit.

35 Ibidem; DE LA CADENA, Marisol, 20I4, op. cit.

36 CORSÍN JIMÉNEZ, Alberto; WILLERSLEV, Rane. An anthropological concept of the concept: reversibility among the Siberian Yukaghirs. Journal of the Royal Anthropological Institute, v. I3, n. 3, 2007, p. 527-544.

37 STRATHERN, Marilyn. Sharing, stealing and borrowing simultaneously. In: STRANG, Veronica; BUSSE, Mark (Org.). Ownership and appropriation. London: Bloomsbury Publishing, 20II, p. 23-42. 
ameaçou-a dizendo: "Uma pulga nunca vai derrotar um elefante"38. Desmentindo o refrão, "a mulher que não vai sair" foi a julgamento e, com a ajuda de sua advogada, derrotou a empresa de mineração em pelo menos duas ocasiões. Explicando o sucesso dessas mulheres nas mídias de notícias centrais, os comentaristas imitam o "homem-empresa" e expressam sua surpresa em narrativas que comparam a sua luta com a de Davi contra Golias. Na verdade, existe público para essa história; o que não é público nessa história sem dúvida surpreendente é que os conceitos que a pulga e o elefante (ou Davi e Golias) empregam são ambos, o mesmo e não apenas.

Além da surpresa, a complexidade é implacável nessa história: a advogada de Máxima, uma mulher de ética profissional impecável e prática profissional inteligente, confia na veracidade dos títulos que representam a propriedade da mulher na terra e está convencida das táticas fraudulentas com as quais a mina tenta deslegitimar esses documentos - ainda assim, ela também acha que a vontade de Máxima de permanecer na terra excede a argumentação legal. Em um trabalho recente, Isabelle Stengers diz o seguinte: "O que é adequado a cada evento é que ele traz o futuro que herdará disso em uma comunicação com um passado narrado de forma diferente" ${ }^{39}$. Se consideramos a recusa de Máxima em vender como um excesso para a propriedade moderna (e não apenas como um "conflito em relação à mineração" que pode ser resolvido para que "tudo possa voltar ao normal"), ela também pode estar inscrevendo um evento: ela pode estar criando um refúgio para a vida - incluindo rochas e água e muitas outras coisas sem as quais não há vida) longe da destruição em que o que atualmente passa como progresso é predicado. Ela pode estar criando possibilidades para um futuro alternativo, um futuro em que herdar da teimosia de Máxima por ficar e defender a vida faria possível narrar o passado - isto é, nosso presente - de uma maneira diferente.

\section{UM FIM ESPERANÇOSO: UMA NATUREZA INCOMUM OU UM COMUM DIVERGENTE ${ }^{40}$}

A história de Máxima - como as dos Mapuche, dos AwajunWampi e dos Runakuna - é uma história do antropo-cego; embora pareçam ocorrer em todos os lugares, os eventos são locais. Contadas com ênfase no local, as narrativas podem expor complexidades que desestabilizam gramáticas lineares e levam conceitos a seus limites. Ouvidas com cuidado, elas revelam que os conflitos que eles narram podem incluir um dissenso que não encontra uma resolução fácil porque excede o domínio

38 Máxima AcuNa: "Me dijeron: Una pulga nunca le va a ganar a un elefante". Disponível em: <https://www. youtube.com/watch?v=5dFm5JuUzIA $>$. Acesso em: 24 jan. 2018.

39 STENGERS, Isabelle. In catastrophic times: resisting the coming barrarism. Trad. Andrew Goffey. Open Humanities Press; Meson Press, 2015.

40 A divergência é uma noção que eu empresto de Isabelle Stengers. Refere-se à diferença constitutiva que torna as práticas o que elas são $e$ à medida que se conectam por meio da diferença, mesmo da diferença ontológica. Ver: STENGERS, Isabelle. introductory notes on an ecology of practices. Cultural Studies Review, v. II, n. I, 20I3, p. I83-I96. 
existente da lei, a saber, a concepção e a regulação da natureza como recursos. Considerando (ao invés de negar) a possibilidade do excesso - a saber, a afirmação de que a natureza não é apenas isso, ou que os materiais que a fazem também são específicos de um lugar e podem incluir os seres humanos -, essas histórias podem abrir o pensamento e o sentimento para não apenas o que são nossos sentidos comuns. $O$ requisito para essa abertura pode ser uma disposição para dar uma chance política ao equívoco. Isso significa uma disposição para considerar que o que é hegemônico - por exemplo, a natureza (para continuar com o mesmo tema) - também pode ser diferente da natureza, mesmo que ocupe o mesmo espaço: não apenas um rio, também uma pessoa; não apenas água universal, também água local; não apenas montanhas, também seres da terra; não só terra, também Ixofijmogen.

Nas páginas que se seguem, concluo esta intervenção com uma especulação sobre a composição de uma aliança política que acolha acordos que aceitem a possibilidade de equívocos, acordos feitos não entre diferentes pontos de vista sobre o mesmo mundo, mas levando em consideração que os pontos de vista possam corresponder a mundos que não são apenas os mesmos. Especulo usando a história dos guardiões da lagoa que a insubmissão de Máxima tornou famosa e a partir da qual fez frutificar tanta esperança. Ele ilustra o desejo de Haraway de contar histórias "amplas o suficiente para reunir as complexidades e manter as fronteiras abertas e insaciáveis por novas e surpreendentes conexões".

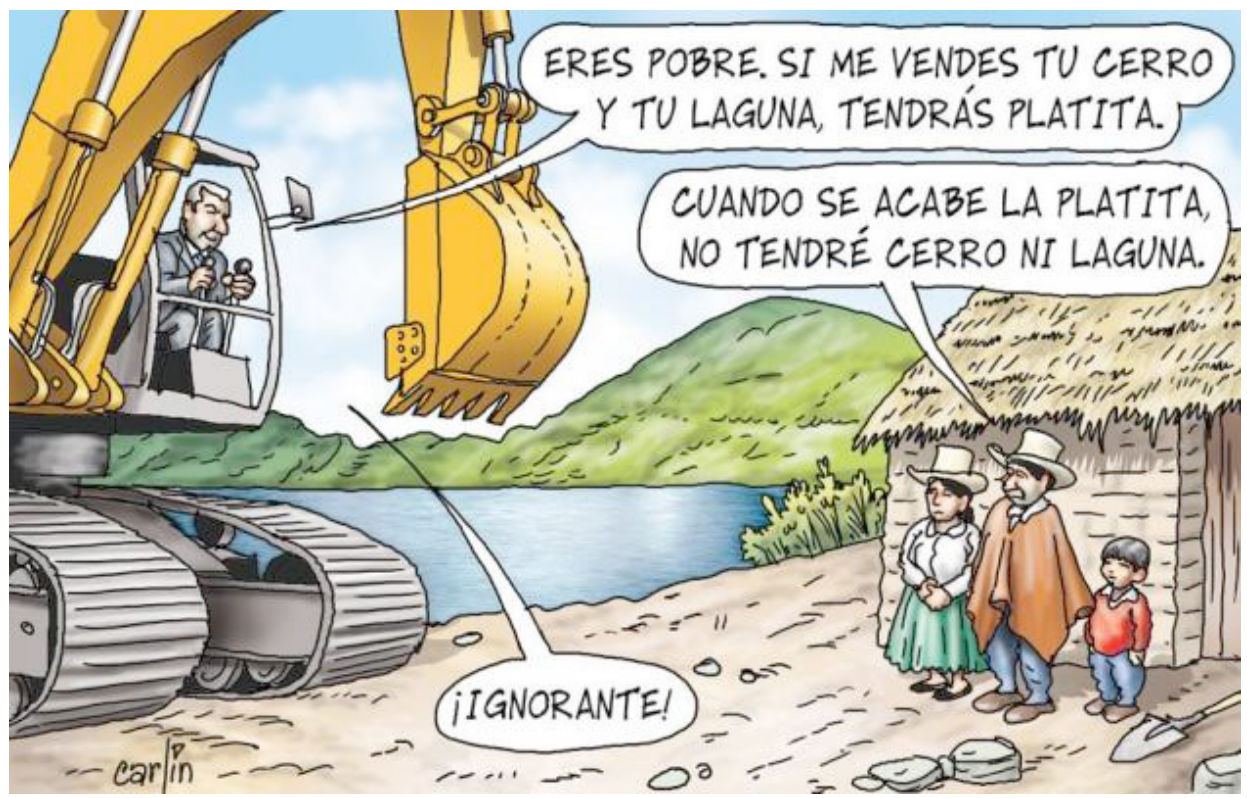

Figura I - Alianças complexas contra o extrativismo. O homem que dirige a retroescavadeira diz à família camponesa: "Você é pobre. Se você vender sua montanha e sua lagoa para mim, terá dinheiro". A resposta da família: "Uma vez que o dinheiro tiver sido gasto, não vou ter nem montanha nem lagoa". O homem: "Ignorante!" 
Confrontada com a proposta da empresa mineira de dessecar as lagoas, uma rede heterogênea de ambientalistas apoiou os guardiões locais contra a empresa de mineração. A ilustração que incluo aqui reflete a aliança: um participante da aliança, seu autor zomba dos esforços da corporação para convencer uma família camponesa racional que, confrontada com a decisão entre a escolha de um dinheiro finito e terra duradoura, usa sujeito e objeto de gramática e benefício econômico lógico para sensatamente escolher o último. Da mesma forma, por meio de uma extensão global dessa rede, Máxima recebeu o Goldman Environmental Prize, um prêmio muito importante em homenagem a líderes de base ${ }^{4}$. Essas alianças são, no entanto, complexas. Ocupando o mesmo espaço (que "não pode ser mapeado em termos de um único conjunto de coordenadas tridimensionais") ${ }^{42}$, formas heterogêneas (natureza universal, ambiente, água que resiste à tradução para $\mathrm{H}_{2} \mathrm{O}$, terra que é objeto e não é, entidades que chamo de natureza ecologizada - ou natureza insubmissa à universalidade) convergem na rede por meio de acordos que não impedem as diferenças.

Por exemplo, diferindo da opinião do cartunista, a segurança econômica de sua família pode não figurar como definida na recusa de Máxima em vender ${ }^{43}$; no entanto, ambos concordam que não se deve vender. Da mesma forma, o interesse que os ambientalistas e os guardiões das lagoas compartilham - defender a natureza ou o meio ambiente - pode não ser apenas o mesmo interesse: a natureza ecologizada localmente dos guardiões e a natureza biologicamente definida de ativistas ambientais (globais e nacionais) podem realmente se exceder, pois não são apenas da mesma natureza. No entanto, ambos os casos abrigam a possibilidade de um acordo que, ao invés de convergir para interesses idênticos, seria sustentado por "incomunidades": interesses em comum que não são o mesmo interesse. Esse acordo fala da possibilidade de uma aliança alternativa, que, juntamente com as coincidências, pode incluir a divergência constitutiva das partes: elas podem convergir sem se tornarem as mesmas. Esse acordo poderia incluir uma discussão sobre o mundo único como uma condição ontológica que os participantes da aliança não compartilham de forma homogênea e que, consequentemente, pode ser uma fonte de fricção entre eles ${ }^{4}$.

Sustentada por termos que poderiam vir a alterar a política como costumamos

4I Máxima AcuNa. 2016 Goldman Prize Recipient South and Central America. Disponível em: <https://www. goldmanprize.org/recipient/maxima-acuna/>. Acesso em: 24 jan. 2018.

42 MOL, Annemarie; LAW, John. Complexities: social studies of knowledge practices. Durham: Duke University Press, 2002.

43 Em uma entrevista recente, por exemplo, Máxima declarou: “Eu prefiro não ter dinheiro. Minha terra me faz feliz, o dinheiro não”. Ver: Maxima AcuNa, la dama de la laguna azul versus la laguna negra. Disponível em: 〈http://etiquetanegra.com.pe/articulos/maxima-acuna-la-dama-de-la-laguna-azul-versus-la-laguna-negra . Acesso em: 8 mar. 20I6..

$44 \mathrm{O}$ argumento de que um mundo único é compartilhado de forma heterogênea é uma das principais ideias de Law. O que acrescento aqui é que a aliança abarca a possibilidade de discussão dessa condição. Ver: LAW, John. What's wrong with a one-world world?. Distinktion Scandinavian Journal of Social Theory, v. I6, n. I, 20I5, p. I26-I39. 
ver, essa aliança também traria esperança por um bem comum que não exige a divisão entre uma natureza universal e humanos diversificados. Os bens comuns que emergem constantemente dos incomuns como base para a negociação política do que seria o interesse em comum - e, portanto, dos bens comuns. Um bem comum que não pode existir sem ser com os incomuns: em vez da expressão de relações compartilhadas e de manejo da natureza, esse comum seria a expressão da produção de muitos mundos ecologicamente relacionados em toda a sua divergência constitutiva. Como uma prática de vida que cuida de interesses em comum (sem exigir que coincidam como mesmo interesse), a aliança entre ambientalistas e guardiões locais (de lagoas, rios, florestas) poderia se envolver em conversa que leve em consideração a hegemonia da distribuição ontológica do mundo em uma natureza universal e humanos diferenciados localmente, sem, no entanto, considerar tal distribuição como um requisito. A aliança expressaria assim um confronto com o acordo que estabelecia o antropo-cego, questionando a legitimidade da guerra contra aqueles que não concordavam com essa distribuição. A divisão do mundo em humanos diversificados e uma natureza homogênea - ou melhor, e mais radicalmente, a fabricação do mundo em um só por meio da imposição da homogeneidade de tal partição - poderia se tornar uma questão de pertinência política. Assim, a exigência de semelhança ontológica feita pela política moderna poderia ser questionada e, juntamente com ela, viria uma nova consequência: o dissenso sobre as formas de fazer do mundo (ou seja, a política ontológica) poderia ocorrer entre aqueles que compartilham a semelhança ontológica (ou seja, aqueles que produzem mundo de maneiras semelhantes). Um exemplo dessa possibilidade é o dissenso entre a empresa de mineração que quer expulsar "a mulher que não quer sair" e a advogada que a defende. A aliança entre as duas mulheres revela lados diferentes da mesma moeda. Uma aliança entre mundos que não apenas não são o mesmo; o que os aproxima é um interesse em comum que não é o mesmo interesse: seus interesses se excedem mutuamente, visto que as duas mulheres convergem em uma noção complexa de propriedade - sustentando suas formas divergentes de ser com a água, a terra, os animais - e entrando em uma relação de antagonismo com a mineradora.

Essas alianças inesperadas podem ter surgido com o extrativismo, que, estimulado pelos preços dos minerais e as políticas neoliberais, foi se tornando aparentemente indomável e acelerou a definição da natureza como sinônimo dos recursos que ela também torna onipresentes. O paradoxo pode ser que a crueldade do extrativismo tenha feito surgir coletividades públicas para as quais a natureza não é apenas isso, e que se opõem à destruição (extrativista) de quem são (e não apenas da natureza) em uma nova aliança com ambientalistas (para quem pode ser que a natureza seja apenas a natureza). O extrativismo é o tropo por meio do qual o Antropoceno se faz presente na região e, como em uma escala planetária, ameaça com a destruição do que o torna possível, terminando com a aniquilação gradual da própria vida. Visto por meio do extrativismo - incluindo a oposição a ele - o Antropoceno poderia ser um momento histórico de implosão, quando a guerra contra as práticas desobedientes de produção de mundo se voltou contra o mundo que a travava e, ao fazê-lo, revelou também a impossibilidade de destruição de mundos que excedeu primeiro 
a palavra de Deus e, mais tarde, a palavra do homem moderno - tanto capitalista quanto socialista. Defendendo-se da destruição atual, os coletivos que excedem as divisões entre "humano" e "não humano" tornaram-se visíveis manifestando seu excesso: sua materialidade não é apenas a materialidade do antropos moderno. A resistência à guerra do antropo-cego irrompe no público, afirmando o seu ser e clamando por uma política que vá além dos direitos que o Estado poderia ou não oferecer benevolentemente por meio da cultura. Muito longe de ser um "conflito como costumamos ver", seu dissenso com o Estado pode dizer respeito à soberania territorial, e não apenas. Pode expressar a demanda pública por permitir condições políticas, historicamente negadas, de que "sem natureza não há cultura"45. O silêncio que encobriu a guerra contra as práticas desobedientes de produção de mundo pode chegar ao fim; a sua destruição (e a luta contra ela) pode ser vista de forma ubíqua em todos os tipos de telas. Paradoxalmente, a era do Antropoceno pode testemunhar o histórico fim do antropo-cego.

SOBRE A AUTORA

MARISOL DE LA CADENA é professora associada do Departamento de Antropologia da Universidade da Califórnia (UC Davis).

E-mail: mdelac@ucdavis.edu

\section{REFERÊNCIAS BIBLIOGRÁFICAS}

BEBBINGTON, Anthony. Political ecologies of resource extraction: agendas pendientes. Revista Europea de Estudios Latinoamericanos y del Caribe, n. I00, 20I5, p. 85-98.

CABALLERO, Antonio. Mil palabras por una imagen. Miseria artificial. Arcadia, 20I6. Disponível em: <http://www.revistaarcadia.com/opinion/columnas/articulo/antonio-caballero-escribe-sobre-laguajira-y-saqueo-a-los-indigenas-wayuu/47708>.

CORSÍN JIMÉNEZ, Alberto; WILLERSLEV, Rane. An anthropological concept of the concept': reversibility among the Siberian Yukaghirs. Journal of the Royal Anthropological Institute, v. I3, n. 3, 2007, p. 527-544.

DE LA CADENA, Marisol. Human but not only. HAU: Journal of Ethnographic Theory, v. 4, n. 2, 2014, p. 253-259.

. Earth beings: ecologies of practice across Andean worlds. Durham: Duke University Press, 2015. . Indigenous cosmopolitics in the Andes: conceptual reflections beyond "politics". Cultural Anthropology, v. 25, n. 2, 2010, p. 334-370.

45 STRATHERN, Marilyn; MACCORMACK, Carol. No Nature. No Culture. The Hagen Case. In: STRATHERN, Marilyn (Org.). Nature, Culture, and Gender. Cambridge: Cambridge University Press, I980, p. I74-22I. 
DELEUZE, Gilles. Bartleby; or the formula. In: . Essays critical and clinical. New York: Verso Books, I998, p. 68-9I.

DELEUZE, Gilles; GUATTARI, Felix. What is philosophy?. New York: Columbia University Press, I994.

FOUCAULT, Michel. Society must be defended. Lectures at the Collège de France, I975-I976. Trad. David Macey. New York: Picador, 2003.

GUDYNAS, Eduardo. Extractivismos. Ecología, economía y política de un modo de entender el desarrollo y la naturaleza. La Paz: Cedib, 2015.

HARAWAY, Donna. Anthropocene, Capitalocene, Plantationocene, Chthulucene: Making Kin. Environmental Humanities, v. 6, 20I5, p. I59-I65.

HARVEY, Penelope; KNOX, Hannah. Roads. An anthropology of infrastructure and expertise. Ithaca: Cornell University Press, 2015.

HOWE, Cymene; BOYER, Dominic; BARRERA, Edith. Wind at the margins of the state: autonomy and renewable energy development in Southern Mexico. In: MCNEISH, John-Andrew; BORCHGREVINK, Axel; LOGAN, Owen (Org.). Contested powers. The politics of energy and development in Latin America. London: Zed Books, 2015.

LATOUR, Bruno. War of the worlds. What about peace?. Trad. Charlotte Bigg. Chicago: Prickly Paradigm Press, 2002.

LAW, John. After method: mess in social science research. New York: Routledge, 2004. . What's wrong with a one-world world? Distinktion Scandinavian Journal of Social Theory, v. I6, n. I, 20I5, p. I26-I39.

MICHAEL, Warner. Publics and counterpublics. Brooklyn: Zone Books, 2005.

MICHEL, Serres. Malfeasance. Appropriation through pollution?. Stanford: Stanford University Press, 20II. MOL, Annemarie; LAW, John. Complexities: social studies of knowledge practices. Durham: Duke University Press, 2002.

NAVARRO, Santiago; BESSI, Renata. Fracking expands in Latin America, threatening to contaminate world's third-largest aquifer. December II, 20I5. Disponível em: <https://www.alternet.org/fracking/ fracking-expands-latin-america-threatening-contaminate-worlds-third-largest-aquifer $>$. Acesso em: 24 jan. 2018.

RANCIÈRE, Jacques. Disagreement: politics and philosophy. Minneapolis: University of Minnesota Press, I999.

SHANE, Greene. Making old histories new in the Peruvian Amazon. Anthropology Now, v. I, n. 3, 2009, p. 52-60. Disponível em: <www.academia.edu/649566/Making_Old_Histories_New_in_the_Peruvian_Amazon_Bagua >.

STAR, Susan Leigh; GRIESEMER, James R. Institutional ecology, translations and boundary objects: amateurs and professionals in Berkeley's Museum of Vertebrate Zoology, 1907-39. Social Studies of Science, v. I9, n. 3, I989, p. 387-420.

STENGERS, Isabelle. In catastrophic times: resisting the coming barrarism. Trad. Andrew Goffey. [s.l.]: Open Humanities Press; Meson Press, 2015.

. Introductory Notes on an Ecology of Practices. Cultural Studies Review, v. II, n. I, 20I3, p. I83-I96.

STRATHERN, Marilyn. Sharing, stealing and borrowing simultaneously. In: STRANG, Veronica; BUSSE, Mark (Org.). Ownership and appropriation. London: Bloomsbury Publishing, 20II, p. 23-42.

. No Nature. No Culture. The Hagen Case. In: STRATHERN, Marilyn; MACCORMACK, Carol (Org.). Nature, culture, and gender. Cambridge: Cambridge University Press, I980, p. I74-22I.

SVAMPA, Maristella. Commodities consensus: neoextractivism and enclosure of the commons in Latin America. The South Atlantic Quarterly, v. II4, n. I, 20I5, p. 65-82. 
VALERIE, Kuletz. The tainted desert: environmental and social ruin in the American West. New York: Routledge, I998.

VIVEIROS DE CASTRO, Eduardo. Perspectival anthropology and the method of controlled equivocation. Tipití: Journal for the Society of Anthropology of Lowland South America, v. 2, n. I, 2004, p. 3-22.

EL PANTANOSO caso Chaupe. Disponível em: <http://larepublica.pe/politica/858259-el-pantanoso-casochaupe >. Acesso em: 24 jan. 2018.

LOS SUCESOS de Bagua. Disponível em: 〈http://www.servindi.org/producciones/videos/13083〉. Acesso em: 20 jun. 2009.

PARA PERICO la territorialidad no era solo un concepto. Disponível em: <http://www.servindi.org/actualidad-noticias-radioteca-videos/29/oI/20I6/para-perico-la-territorialidad-no-era-solo-un >. Acesso em: 27 fev. 2016.

PRONUNCIAMIENTO de Santiago Manuín Contra la Petición de Cadena Perpetua Hacia su Persona. 20I4. Disponível em: 〈http://www.justiciaviva.org.pe/webpanel/doc_int/doc050620I4-I44759.pdf〉. Acesso em: I jun. 2016.

UN VIAJE a las entrañas de Vaca Muerta, El Futuro energetico del país. Disponível em: <http://misionesonline.net/2015/03/o7/un-viaje-a-las-entranas-de-vaca-muerta-el-futuro-energetico-del-pais >. Acesso em: 6 jul. 2015.

VACA MUERTA: “Una situación urgente que no da para más”. Disponível em: <http://www.argenpress. info/20I4/Io/vaca-muerta-una-situacion-urgente-que.html>. Acesso em: 24 jan. 2018. 